\title{
Do eating disorders accompany metabolic syndrome in psoriasis patients? Results of a preliminary study
}

This article was published in the following Dove Press journal:

Clinical, Cosmetic and Investigational Dermatology

27 August 201I

Number of times this article has been viewed

\author{
Ilknur Altunay' \\ Gulsen Tukenmez Demirci' \\ Bilge Ates' \\ Aslı Kucukunal' \\ Cigdem Aydın² \\ Oguz Karamustafalıoglu ${ }^{3}$ \\ Yuksel Altuntas ${ }^{4}$ \\ 'Dermatology Department, Sisli Etfal \\ Training and Research Hospital, \\ Istanbul, Turkey; ${ }^{2}$ Psychology \\ Department, Istanbul University, \\ Istanbul, Turkey; ${ }^{3}$ Psychiatry \\ Department, Sisli Etfal Training and \\ Research Hospital, Istanbul, Turkey; \\ ${ }^{4}$ Internal Medicine Endocrinology \\ Department, Sisli Etfal Training and \\ Research Hospital, Istanbul, Turkey
}

Correspondence: Ilknur Altunay Sisli Etfal Eğitim ve Araștırma Hastanesi, Dermatoloji Kliniği, 19 Mayıs Cad Etfal Sok PK, 34377 Istanbul, Turkey

Tel +902123735000

$\mathrm{Fax}+902123535076$

Email ialtunay@gmail.com
Background: Metabolic syndrome (MBS) has been reported as a frequent comorbidity in psoriatic patients. The main pathogenesis is considered to be inflammation in this association. MBS has been investigated in eating disorders as well. While psoriasis has some psychiatric comorbidities, the link between psoriasis, MBS, and eating disorders (EDs) is unknown.

Methods: The study was designed as a cross-sectional, randomized, and controlled trial. A total of 100 patients with psoriasis were included in the study. Sociodemographic data, clinical subtype of psoriasis, Psoriasis Area and Severity Index (PASI) scores, and associated diseases were registered for each patient. The criteria for diagnosis of MBS developed by the International Diabetes Foundation (IDF) was used. These are central obesity (waist circumference $\geq 94 \mathrm{~cm}$ in men or $\geq 80 \mathrm{~cm}$ in women), plus two of the following: elevated triglycerides ( $\geq 150 \mathrm{mg} / \mathrm{dL}$ ), reduced high-desity lipoprotein cholesterol ( $>40 \mathrm{mg} / \mathrm{dL}$ for men; $>50 \mathrm{mg} / \mathrm{dL}$ for women), elevated blood pressure ( $\geq 130 \mathrm{mmHg}$ systolic or $\geq 85 \mathrm{mmHg}$ diastolic), and elevated fasting blood glucose ( $\geq 100 \mathrm{mg} / \mathrm{dL}$ ). Additionally, the Eating Attitude Test (EAT), Beck Depression Inventory (BDI), and Beck Anxiety Inventory (BAI), and psychiatric interview were performed for all patients.

Results: There were 45 female and 55 male patients, aged between 18 and 85 years old (median $41.12 \pm 16.01)$. MBS was present in $31 \%$ of the patients with psoriasis. There was no correlation between the severity of psoriasis and MBS. EAT scores were $\geq 30$ in $7 / 100$ patients. Four out of 31 patients with MBS (12.9\%) had ED and 3/69 patients were without MBS (4.3\%). Mean ED scores were compared statistically and the difference was significant $(\mathrm{EAT}=17.9 \pm 9.558$ and $11.5 \pm 7.204, P<0.001)$.

Conclusion: Defining risk factors leading to comorbidities is important in psoriasis. EDs seem to have an impact on the development of MBS in psoriasis. Establishment and treatment of EDs in patients with psoriasis may prevent the onset of MBS and other comorbidities due to MBS

Keywords: obesity, abdominal obesity, binge-eating disorder, anxiety, inflammation

\section{Introduction}

Psoriasis is a chronic inflammatory skin disease. Variable immunological and inflammatory processes play a role in pathogenesis and also contribute to occurrence of comorbidities. While the more common concomitant disorders are psoriatic arthritis and depression/anxiety, research papers of comorbidities due to metabolic disregulation and resultant metabolic syndrome (MBS) gradually increase. ${ }^{1-8} \mathrm{MBS}$ is particularly important, because it includes a cluster of risk factors such as central obesity, hypertension, abnormal glucose intolerance, and dyslipidemia, all of which are strong 
predictors of cardiovascular disease, diabetes mellitus, and stroke. ${ }^{9-11}$ All these comorbidities are complex and are supposed to share common pathogenetic pathways and cytokine profiles with psoriasis. Moreover, it is also important to be aware of some predisposing factors, such as sedentary life style, smoking, and alcoholism, which have been previously considered to be facilitating factors for the development of MBS in patients with psoriasis. ${ }^{12}$

Eating disorders (EDs) are characterized by clinically significant disturbances in eating behavior. They are often accompanied by another psychiatric disorder such as depression and anxiety. Particularly, binge-eating disorder (BED) may be associated with obesity and MBS. ${ }^{12,13}$ Hence, it is logical to consider that EDs are psychogenic cofactors which may contribute to the development of MBS in psoriatic patients who are also prone to various psychiatric comorbidites; for example, depression and anxiety. ${ }^{14-16}$

While a few studies demonstrate a link between MBS and EDs, ${ }^{17-19}$ there are also some studies implicating a relationship between EDs and anxiety. ${ }^{20-22}$ If there is a relationship between EDs and psoriasis, diagnosing any ED would be useful for suggesting a change in eating behavior of a psoriatic patient with MBS and thus improve resultant MBS.

\section{Materials and methods}

The study was designed as a cross-sectional, randomized, and controlled trial. A total of 100 patients with psoriasis (55 males, 45 females, age range 18-85, mean age $41.12 \pm 16.01)$ were included in the study. Sociodemographical data including sex, age, marital status and educational status, clinical subtype of psoriasis, psoriasis area severity index (PASI) scores, and other systemic diseases were registered for each patient. Additionally, Eating attitudes Test (EAT), Beck Depression Inventory (BDI), and Beck Anxiety Inventory (BAI) were performed on all patients.

EAT-26 is a widely used self-report measure of EDs, and although it was developed by Garner and Garfinkel in $1979^{23}$ to measure symptoms of anorexia nervosa (AN), it has been used in nonclinical samples as a general screening measure for disordered eating attitudes. EAT-26 is based on EAT-40 and was adapted to Turkish by Erol and Savasir in $1989 .{ }^{24}$ Total scores on EAT-26 are derived as a sum of the composite items, ranging from 0 to 53, with a score of 20 used as the cutoff. ${ }^{24}$ The Turkish version of EAT consists of 40 questions, the answers to which are evaluated with a six-point Likert scale, from "always" to "never." The resulting scores range between 0 and 120 points, and individuals scoring $\geq 30$ points are considered as at high risk of EDs. ${ }^{24}$
The Turkish versions of BDI and BAI, reliability and validity studies of which had been previously performed in the Turkish population, were used. ${ }^{25-28}$

All patients were evaluated for the presence of MBS. The criteria developed by the International Diabetes Foundation for diagnosis of MBS was used. These criteria are central obesity (waist circumference $\geq 94 \mathrm{~cm}$ in men or $\geq 80 \mathrm{~cm}$ in women), plus two of the following: triglycerides $\geq 150 \mathrm{mg} / \mathrm{dL}$; high-desity lipoprotein cholesterol $<40 \mathrm{mg} / \mathrm{dL}$ for men or $<50 \mathrm{mg} / \mathrm{dL}$ for women; blood pressure $\geq 130 \mathrm{mmHg}$ systolic or $\geq 85 \mathrm{mmHg}$ diastolic; and fasting blood glucose $\geq 100 \mathrm{mg} / \mathrm{dL}$. Two study groups were formed according to these criteria. Group 1 consisted of the patients who met MBS criteria, and Group 2 consisted of the patients who did not meet MBS criteria. These two groups were compared statistically in terms of sociodemographical factors and the presence of MBS, EDs, depression, and anxiety. The patients who had an ED according to EAT were also evaluated by a psychiatrist, and the ED was confirmed by psychiatric examination and Diagnostics and Statistical Manual of Mental Disorders, 4th edition criteria. ${ }^{29}$

Patients who were found to have an ED were assessed according to EAT, and a psychiatric interview was done by a psychiatrist. The patients were classified as having $\mathrm{AN}$, bulimia nervosa $(\mathrm{BN}), \mathrm{BED}$, or an ED not otherwise specified (ED-NOS). Independent samples $t$-test, Mann-Whitney $U$-test, chi-square test, Fisher's exact test, and SPSS Statistics 11.5 (IBM Corporation, Somers, NY) software for Windows ${ }^{\circledR}$ were used for statistical assessments. $P<0.05$ was considered statistically significant.

\section{Results}

Group 1 consisted of 31 patients with MBS (31\%, mean age $48.5 \pm 13.4)$, and Group 2 consisted of 69 patients (69\%, mean age $37.7 \pm 16.0$ ). When the two groups were compared, all parameters including sex, marital status, educational status, disease duration, type of psoriasis according to onset age (type I and type 2), and disease severity determined by PASI values except for age were statistically insignificant (Table 1). EAT scores were $\geq 30$ in 7 out of 100 patients. Four out of 31 patients with MBS (12.9\%) and 3 out of 69 patients without MBS (4.3\%) had an ED. However, statistical evaluation was impossible because of low numbers of patients; therefore, mean ED scores were evaluated and a statistically significant difference was found $(\mathrm{EAT}=17.9 \pm 9.558$ and $11.5 \pm 7.204$, $P<0.001$ ) (Figure 1). In psychiatric evaluation, three out of four patients $(75 \%)$ had BED and one $(25 \%)$ had ED-NOS in 
Table I Demographic and clinical characteristics of psoriatic patients with MBS and without MBS

\begin{tabular}{llll}
\hline & $\begin{array}{l}\text { Patients } \\
\text { with MBS } \\
(\mathbf{n}=\mathbf{3 1})\end{array}$ & $\begin{array}{l}\text { Patients } \\
\text { without MBS } \\
\mathbf{( n = 6 9 )}\end{array}$ & $\mathbf{P}$ \\
\hline Sex, male/female & $17 / 14$ & $38 / 31$ & 0.983 \\
Age, mean \pm SD & $48.55 \pm 13.46$ & $37.78 \pm 16.03$ & 0.002 \\
$\begin{array}{l}\text { Disease duration, } \\
\text { mean } \pm \text { SD }\end{array}$ & $13.72 \pm 10.65$ & $10.18 \pm 9.54$ & 0.10 । \\
PASI, mean \pm SD & $13.92 \pm 11.01$ & $16.52 \pm 12.32$ & 0.327 \\
PASI > 10, n (\%) & $17(54.8)$ & $36(52.2)$ & 0.851 \\
Type of psoriasis, n (\%) & & & 0.147 \\
Type I & $20(64.5)$ & $54(78.3)$ & \\
Type 2 & II (35.5) & $15(21.7)$ & \\
\hline
\end{tabular}

Abbreviations: MBS, metabolic syndrome; PASI, psoriasis area severity index; $\mathrm{SD}$, standard deviation.

Group 1. Two out of three patients (67\%) had BED, and one $(33 \%)$ had ED-NOS. No patients had AN or BN.

When the relationship between EDs and depression/anxiety scores was considered, mean BAI scores of the patients with an ED were higher than those without an ED, and the statistical difference was significant $(P=0.004)$ (Table 2). In addition, when the presence of anxiety is considered, the difference between the patients with an ED and those without an ED was statistically significant $(P=0.002)$. BDI did not show any correlation with ED scores; thus, the existence of depression was not related to an ED.

The relationship between PASI and other parameters (criteria of MBS, anxiety, and depression) was evaluated statistically. Only the presence of depression revealed a significant difference $(P=0.031)$.

\section{Discussion}

Psoriasis is a chronic, immunologically based, inflammatory disease associated with many comorbidities related to immune-mediated inflammation and metabolic dysregulation. In particular, recent studies have focused on the MBS and its components such as atherogenesis, hypertension, and insulin resistance. It is hypothesized that proinflammatory

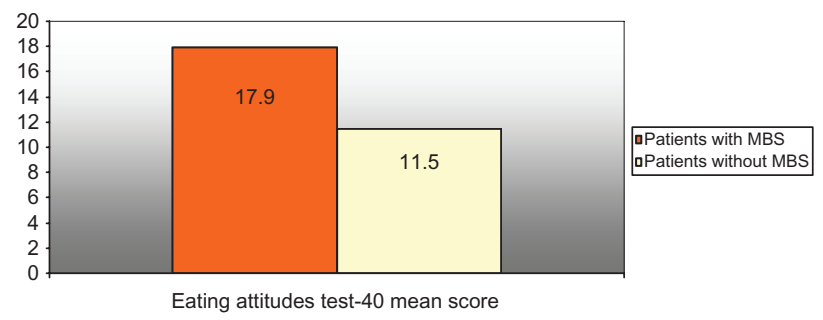

Figure I Mean scores of EAT in patients with MBS and patients without MBS $(E A T=17.900 \pm 9.558$ and II $.500 \pm 7.204, P<0.00 I)$.

Abbreviations: EAT, eating attitudes test; MBS, metabolic syndrome.
Table 2 Beck anxiety and Beck depression mean scores in psoriatic patients with EDs and without EDs (Mann-Whitney U-test; $95 \%$ confidence interval)

\begin{tabular}{|c|c|c|c|}
\hline & \multicolumn{2}{|c|}{ Eating attitudes test- 40} & \multirow[t]{3}{*}{$P$} \\
\hline & $>30$ & $<\mathbf{3 0}$ & \\
\hline & Mean \pm SD & Mean \pm SD & \\
\hline Age & $37.71 \pm 9.55$ & $41.38 \pm 16.40$ & 0.695 \\
\hline PASI & $14.70 \pm 8.08$ & $15.77 \pm 12.17$ & 0.945 \\
\hline Disease duration, years & $7.50 \pm 4.75$ & $11.56 \pm 10.22$ & 0.457 \\
\hline Beck anxiety score (mean) & $21.86 \pm 6.09$ & $11.92 \pm 8.07$ & 0.004 \\
\hline $\begin{array}{l}\text { Beck depression } \\
\text { score (mean) }\end{array}$ & $18.14 \pm 13.36$ & $13.76 \pm 12.01$ & 0.295 \\
\hline
\end{tabular}

Abbreviations: ED, eating disorder; PASI, psoriasis area severity index; SD, standard deviation.

cytokines and pathomechanisms in inflammation are shared in both psoriasis and MBS. ${ }^{1,4}$ In fact, this association alone was proven; it was not considered a causality. Hence, a new problem has emerged with additional risk factors such as cigarette smoking, excessive alcohol consumption, and obesity, which predispose psoriatic patients to develop MBS. ${ }^{4,14-16}$ This hypothesis was reinforced by Alsufyani et al. ${ }^{4}$ They suggested that speculation exists as to whether this association is causative or whether it is the result of other habits seen in psoriasis patients, such as increased rates of smoking, alcohol consumption, and sedentary lifestyle, which add to the complexity of the association between psoriasis and MBS.

Some authors proposed that abnormal eating behavior associated with a sedentary lifestyle may contribute to the development of obesity. ${ }^{14}$ This was previously demonstrated in some studies, in particular for BED, short-term overeating, and ED-NOS. ${ }^{30-32}$ BED is characterized by recurrent episodes of binge eating. In fact, binge eating behaviour which is also seen in many cases of $\mathrm{AN}$ and $\mathrm{BN}$ is the main characteristic of ED. Although little is known about MBS in obese patients with BED, laboratory studies have shown that eating behaviors frequently found in BED patients may increase the risk of metabolic abnormalities. For example, in one study, increased eating rate has been demonstrated to be associated with central obesity, elevated serum lipids, and fatty liver. ${ }^{32}$ The results of a longitudinal study conducted by Hudson et al showed that BED may increase the risk of components of MBS independent of the risk conferred by obesity alone. ${ }^{18}$ Interestingly, metabolic abnormalities have even been observed in healthy lean women following laboratory-based binge-like episodes. ${ }^{33}$ The fact that the mean ED score was higher in psoriatic patients with MBS than in those without MBS is in accordance with literature data implicating a link between MBS and ED. ${ }^{32,34}$ However, the 
number of patients was inadequate for statistical comparison for EDs. This may be a limitation of this present study. More reliable or indicative results are likely with a larger number of psoriasis patients. When considering the prevalence of EDs, there are different studies in different populations. Women, children, adolescents, and the obese have been the principal subjects for prevalence studies. ${ }^{32,35-37}$ In a largescale prevalence study including six European countries, AN $0.48 \%$, BN $0.51 \%$, and BED $1.12 \%$ were found.$^{38}$ Therefore, working with larger numbers of patients would probably be more indicative because of the small percentage of real EDs in the general population.

These data raise another question as to why psoriatic patients have EDs. The explanation comes from increased psychiatric comorbidity, in particular depression and anxiety, in psoriatic patients. ${ }^{14,15}$ There are some reports that indicate a link between ED and stress factors including anxiety and depression. ${ }^{20-22,35}$ This means that, in particular, anxiety associated with psoriasis may cause abnormal eating habits and resultant MBS in psoriasis. In a study conducted by Herron et al obesity was suggested as a consequence of psoriasis and not a risk factor for onset of disease. ${ }^{14}$ Accordingly, the authors of this present paper suggest that the interaction between psoriasis, psychiatric symptoms, and EDs may lead to obesity or MBS over time; that these current results showed higher mean age in MBS may reinforce this speculation.

According to this study's findings, clinical severity of psoriasis measured by PASI seems to be an independent variable in the relationship between EDs, MBS, and anxiety.

\section{Conclusion}

In conclusion, it appears that it is not adequate to establish the presence of comorbidities alone; defining risk factors leading to comorbidities is also important in patients with psoriasis. If causative factors are detected, controlling them by a multidisciplinary approach will prevent the onset of comorbidities and also provide both cost-effective and satisfactory management of psoriasis.

\section{Disclosure}

The authors report no conflicts of interest in this work.

\section{References}

1. Nickoloff BJ. The immunologic and genetic basis of psoriasis. Arch Dermatol. 1999;135:1104-1110.

2. Sommer DM, Jenisch S, Suchan M, et al. Increased prevalence of the metabolic syndrome in patients with moderate to severe psoriasis. Arch Dermatol Res. 2006;298:321-328.
3. Gisondi P, Tessari G, Conti A, et al. Prevalence of metabolic syndrome in patients with psoriasis: a hospital-based case-control study. $\mathrm{Br} \mathrm{J}$ Dermatol. 2007;157:68-73.

4. Alsufyani MA, Golant AK, Lebwohl M. Psoriasis and the metabolic syndrome. Dermatol Ther. 2010;23:137-143.

5. Al-Mutairi N, Al-Faraq S, Al-Mutain, et al. Comorbidities with psoriasis: an experience from the Middle East. J Dermatol. 2010;37: 146-155.

6. Christophers E. Comorbidities in psoriasis. Clin Dermatol. 2007;25: 529-534.

7. Kim N, Thrash B, Menter A. Comorbidities in psoriasis patients. Semin Cutan Med Surg. 2010;29:10-15.

8. Guenter L, Gulliwer W. Psoriasis comorbidities. J Cutan Med Surg. 2009; 13:877-887.

9. Wilson PW, D'Agostino RB, Parise H, et al. Metabolic syndrome as a precursor of cardiovascular disease and type 2 diabetes mellitus. Circulation. 2005;112:3066-3072.

10. Eckel RH, Alberti KG, Grundy SM, et al. The metabolic syndrome. Lancet. 2010;375:181-183.

11. Wannamethee SG, Shaper AG, Lennon L, et al. Metabolic syndrome vs Framingham Risk Score for prediction of coronary heart disease, stroke and type 2 diabetes mellitus. Arch Intern Med. 2005;165: 2644-2650.

12. Roehring M, Mashep MR, White MA, Grilo MC. The metabolic syndrome and behavioral correlates in obese patients with binge disorders. Obesity. 2009;17:481-486.

13. Guerdjikova AI, McElroy SL, Kotwal R, Keck PE Jr. Comparison of obese men and women with binge eating disorder seeking weight management. Eat Weight Disord. 2007;12:19-23.

14. Herron MD, Hinckley M, Hoffman MS, et al. Impact of obesity and smoking on psoriasis presentation and management. Arch Dermatol. 2005;141:1527-1534.

15. Haves J, Koo J. Psoriasis: depression, anxiety, smoking and drinking habits. Dermatol Ther. 2010;23:174-180.

16. Kurd SK, Troxel AB, Crits-Christoph P, et al. The risk of depression, anxiety and suicidality in patients with psoriasis: a population-based cohort study. Arch Dermatol. 2010;146:891-895.

17. Vaag A, Brøns C, Apel JS, et al. Metabolic consequences of overeating. Ugeskr Laeger. 2006;168:183-187.

18. Hudson JI, Lalonde JK, Coit CE, et al. Longitudinal study of the diagnosis of components of the metabolic syndrome in individuals with binge-eating disorder. Am J Clin Nutr. 2010;91:1568-1573.

19. Herpetz S, Albus C, Wagener R, et al. Comorbidity of diabetes and eating disorders. Does diabetes control reflect disturbed eating behavior? Diabetes Care. 1998;21:1110-1116.

20. Bulik CM, Sullivan PF, Fear JL, et al. Eating disorders and antecedent anxiety disorders: a controlled study. Acta Psychiatr Scand. 1997;96: 101-107.

21. Godart N, Flament M, Curt F, et al. Are anxiety disorders more frequent in subjects with eating disorders? Ann Med Interne. 2003;154: 209-218.

22. Blinder BJ, Cumella EJ, Sanathara VA. Psychiatric comorbidities of female inpatients with eating disorders. Psychosom Med. 2006;69: 454-462.

23. Garner DM, Garfinkel PE. The eating attitudes test: an index of the symptoms of anorexia nervosa. Pyschol Med. 1979;9:273-279.

24. Erol N, Savaşır I. Eating attitude test: index of anorexia nervosa symptoms. Turkish Journal of Psychology. 1989;23:132-136. [In Turkish, English abstract.]

25. Beck AT, Ward CH, Mendelson M, et al. An inventory for measuring depression. Arch Gen Psychiatry. 1961;4:561-571.

26. Hisli N. Reliability and validity study of Turkish version of Beck depression inventory. Turkish Psychol J. 1988;6:118-122.

27. Beck AT, Epstein N, Brown G, et al. An inventory for measuring clinical anxiety: psychometric properties. J Consult Clin Psychol. 1988; 56:893-897. 
28. Ulusoy M, Erkmen H, şahin N. Turkish version of the Beck anxiety inventory: psychometric properties. J Cogn Psychother. 1998;12: 163-172.

29. American Psychiatric Association. Diagnostic Statistical and Manual of Mental Disorders. 4th ed. Washington, DC: American Psychiatric Association; 1994.

30. Hudson JI, Lalonde JK, Berry JM, et al. Binge-eating disorder as a distinct familial phenotype in obese individuals. Arch Gen Psychiatry. 2006;63:313-319.

31. Danielsson A, Fagerholm S, Ost A, et al. Short-term overeating induces insulin resistance in fat cells in lean human subjects. Mol Med. 2009;15: $228-234$

32. Villagomez L, Cortes J, Barrera E, et al. Comorbidity of obesity and eating behaviour disorders. Rev Invest Clin. 2003;55:535-545.

33. Taylor AE, Hubbard J, Andersen EJ. Impact of binge eating on metabolic and leptin dynamics in normal young women. J Clin Endocrinol Metab. $1999 ; 84.428-434$.
34. Kral JG, Buckley MC, Kissileff HR, et al. Metabolic correlates of eating behavior in severe obesity. Int J Obes Relat Metab Disord. 2001; 25:258-264.

35. Swanson CA, Crow SJ, Le Grange D, et al. Prevalence and correlates of eating disorders in adolescents: results from the national comorbidity survey replication adolescent supplement. Arch Gen Psychiatry. 2011; 68:714-723.

36. Mond JM, Arrighi A. Gender differences in perceptions of the severity and prevalence of eating disorders. Early Interv Psychiatry. 2011; 5:41-49.

37. Mammen P, Russell S, Russell PS. Prevalence of eating disorders and psychiatric comorbidity among children and adolescents. Indian Pediatr. 2007;44:357-359.

38. Preti G, Girolamo G, Vilagut G, et al. The epidemiology of eating disorders in six European countries: results of the ESEM Ed-WMH project. J Psychiatr Res. 2009;43:1125-1132.

\section{Publish your work in this journal}

Clinical, Cosmetic and Investigational Dermatology is an international, peer-reviewed, open access, online journal that focuses on the latest clinical and experimental research in all aspects of skin disease and cosmetic interventions. All areas of dermatology will be covered; contributions will be welcomed from all clinicians and basic science researchers globally. This journal is indexed on CAS. The manuscript management system is completely online and includes a very quick and fair peer-review system, which is all easy to use. Visit http://www.dovepress.com/testimonials.php to read real quotes from published authors.

Submit your manuscript here: http://www.dovepress.com/clinical-cosmetic-and-investigational-dermatology-journal 